\title{
O CONSUMO - REVISÃO TEÓRICA SOBRE AS POSSÍVEIS RAZÕES DO “IR ÀS COMPRAS" POR MEIO DE INFOGRÁFICO
}

\author{
Consumption: Theoretical review of the possible reasons for "going shopping" through \\ the infographic
}

\section{Consumo: Examen teórico de las razones posibles para "going shopping" a través de una infografía}

Tobias Oliveira Camargo ${ }^{1}$

\begin{abstract}
Resumo
O objetivo deste trabalho é promover uma discussão teórica preliminar sobre a sociedade de consumo, com uma breve retomada histórica, e uma discussão sobre como se relacionam autores e teorias deste campo. O infográfico ao final propõe uma síntese genérica com base nas relações encontradas entre as teorias e os autores. A pesquisa bibliográfica aponta que a descoberta e expressão do self, a marcação social, a transferência de significados para os artefatos de acordo com cada cultura e rituais são entendidas como possíveis causas que poderiam levar à atividade de consumo.
\end{abstract}

Palavras-chave: consumismo, sociedade de consumo, pós-modernismo.

\begin{abstract}
This paper aims to promote a preliminary theoretical discussion on the consumer society, with a brief historical summary, and a discussion on how the theories and authors of this field relate. The infographic at the end proposes a general synthesis based on the relationships found between authors and theories. The literature points out that the discovery and selfexpression, social tagging, the transfer of meaning for the artifacts according to each culture and rituals are seen as possible causes that could lead to consumer activity.
\end{abstract}

Keywords: consumerism, society consumption, post-modernism.

\section{Resumen}

\footnotetext{
${ }^{1}$ Mestre em Design Estratégico, UNISINOS, graduado em Design Gráfico pela Faculdade SATC. E-mail: tobiascamargo@gmail.com
} 
O consumo: Revisão teórica sobre as possíveis razões do "ir às compras" por meio de infográfico

de Tobias Oliveira Camargo

Este trabajo tiene como objetivo promover un debate preliminar teórico sobre la sociedad de consumo, con un breve resumen histórico, y una discusión sobre cómo las teorías y autores de este campo se relacionan. La infografía al final propone una síntesis general basada en las relaciones encontradas entre los autores y teorías. La literatura señala que el descubrimiento y la auto expresión, etiquetado social, la transferencia de significado para los artefactos de acuerdo a cada cultura y los rituales son vistos como posibles causas que podrían conducir a la actividad de consumo.

Palabras-clave: consumismo, sociedad de consumo, posmodernismo.

\section{INTRODUÇÃO}

O consumo é um tema discutido, muitas vezes, de maneira informal e carregado de ideologias, até mesmo na academia se encontram pensamentos pautados em uma determinada visão política. Como afirma Miller (1995), para discutir o tema consumismo é preciso fazer uma "faxina ideológica" para evitar uma banalização da questão e permitir uma argumentação que não tenha como base uma visão de direita ou de esquerda (capitalismo x socialismo).

O consumo, embora abordado profundamente em diversas disciplinas em marketing, design, publicidade e administração; por sermos uma sociedade pós-moderna e em constantes mudanças, ainda há um longo caminho a percorrer em seu estudo. Assim, foi observada a necessidade de se colocar em debate teorias relacionados ao consumo, uma vez que esse campo é extremamente amplo, foi proposto um recorte no conhecimento por meio de um estudo exploratório delineado por uma pesquisa bibliográfica que lança mão de autores que abordam temas adjacentes às teorias de consumo. Bauman (2003), Baudrillard (1991) e Lipovetsky (2004) abordam a pós-modernidade. McKendrick (1982), Mukerji (1982) e Williams (1983) trazem uma retomada histórica sobre as possíveis origens da revolução do consumo. Veblen (1983) e Bourdieu (1979) abordam a sociedade e suas relações enquanto que Miller (1995), McCracken (2003), Campbell (2000), Belk (1995), e Douglas (2006) tratam sobre a sociedade de consumo.

Desta forma, este artigo tem por objetivo promover uma discussão teórica preliminar sobre a sociedade de consumo e com base nos autores, discutir os principais motivos que poderiam levar ao consumo, apresentando-os de maneira sintética por meio de um infográfico. O primeiro capítulo será dividido em três tópicos principais, sendo eles: 
O consumo: Revisão teórica sobre as possíveis razões do "ir às compras" por meio de infográfico

de Tobias Oliveira Camargo

Contextualização histórica, que procura apresentar como foi o consumo ao longo dos séculos e quais as principais teorias produzidas; Pós-modernidade, que com base no histórico irá discutir como é a sociedade atual e o porquê da sua influência no processo de consumo. Por último, será abordado o tópico Consumo, onde pretende-se discutir de maneira concisa os conceitos relacionados aos principais motivos que podem levar sujeitos ao ato de consumir a partir dos autores citados. Posteriormente, é apresentada uma síntese geral da discussão por meio de um infográfico, respondendo ao objetivo proposto.

Com este trabalho não se pretende abordar o Consumo como um todo, nem trazer em discussão todos os conceitos a este relacionado. O que se almeja realizar aqui é apenas tratar de forma breve e com base em autores restritos os conceitos trazidos por eles e como se relacionam ao consumo. $\mathrm{O}$ intuito do trabalho é reunir estes conceitos de forma resumida em um infográfico, baseado nas relações encontradas entre autores e teoria.

\section{SOCIEDADE DE CONSUMO}

A palavra "consumo" tem sua origem no Latim "consumere", que significa destruir, gastar, esgotar. É formada por o prefixo “com”, que possui um significado "intensificativo”, e de um radical "suemere", que pode ser entendido como apoderar-se, tomar, agarrar. Enquanto que a "sociedade" tem origem no Latim na palavra "societas", que significa convívio mútuo e união. (CUNHA, 2010) Portanto, pode ser entendido como pessoas que vivem em um mesmo ambiente e que se apoderam de artefatos, podendo ser intensificado ou não pelas necessidades. No próximo tópico irá apresentar o quanto sociedade e consumo estão entrelaçadas desde muito antes do mundo ser estabelecido nos moldes atuais.

\subsection{Contextualização histórica}

Partindo de uma retomada histórica será apresentado de forma sucinta o estudo feito por McCracken (2003), que aborda a visão de McKendrick (1982), Mukerji (1982) e Williams (1983), que procura entender em qual momento histórico se deu a revolução do consumo, contudo, ainda não há um consenso uma definição aceita e compartilhada. McKendrick (1982) afirma que o seu surgimento se deu na Inglaterra no século XVIII. Neste período, a competição social foi à força motriz desta revolução, ou seja, o que no passado era comprado 
O consumo: Revisão teórica sobre as possíveis razões do "ir às compras" por meio de infográfico

de Tobias Oliveira Camargo

como alto luxo passou a ser bons costumes. Este fato alavancou a indústria e a produção em escala e uma maior variedade de produtos, portanto, passou-se gastar mais tempo nas atividades de compras, para escolha e obtenção de informação sobre os melhores benefícios. Foi o início de um fenômeno social conhecido como Trickle-down, que será apresentado posteriormente.

Para Mukerji (1982) a revolução do consumo também se deu no Reino Unido, porém no século XVI durante o reinando de Elizabeth I. Inicialmente como uma forma de governo proposta pela monarca, em que colocava sua corte cada vez mais depende dela. Fez com que os nobres gastassem sua fortuna para manter determinado padrão e fazer parte daquele grupo seleto, como uma competição social - consumo arbitrário e caprichoso - governada pela luxúria. Neste período, a moda passou a ganhar destaque entre os nobres que não viam mais a pátina como sinônimo de riqueza e poder, mas o contrário, ter artefatos novos e que estivessem na moda passariam a representar sua nobreza.

Enquanto Williams (1983) apresenta a revolução do consumo no final do século XIX na França e como a burguesia, que passou a compor as classes mais altas, imitava a antiga aristocracia. Ele observa então, que há uma influência recíproca em diferentes estilos de vida. Sua teoria se aproxima de McKendrick, quando observam as implicações da revolução do consumo para a competição por status.

No século XIX não ocorreu uma revolução do consumo, pois já estava estabelecido como um dos pilares da vida social. São desenvolvidos novos meios de embutir significados nos produtos e transferir novos sentidos, inclusive, surgem novas técnicas de marketing, publicidade e o design. (McCRACKEN, 2003) O que ocorreu foi que o consumo já estava estabelecido em uma relação dinâmica, de modo que as mudanças sociais e de consumo transformaram o ocidente.

Ainda dentro de uma retomada histórica, tomemos o trabalho de Veblen (1983), em que sua primeira edição foi no ano de 1899. Embora seja um trabalho voltado a estudos econômicos, seu ponto central está focado à estratificação e à mobilidade social, ao surgimento da classe ociosa e, ainda, a consolidação da propriedade privada.

Veblen afirma que a classe ociosa - ócio conspícuo - se origina gradualmente ao longo da transição de uma sociedade primitiva e pacífica para uma consistentemente guerreira (bárbara). As funções dignas são aquelas em que intervêm elementos de proeza e façanha, enquanto que as atividades diárias são taxadas de indignas. As pessoas que compunham a 
O consumo: Revisão teórica sobre as possíveis razões do "ir às compras" por meio de infográfico

de Tobias Oliveira Camargo

classe ociosa não tinham a necessidade de trabalhar, não se dedicavam às atividades vis ou industriais. Suas atividades ficavam restringidas às ocupações governamentais, guerreiras, religiosas e esportivas.

Ainda com o autor, algo que começa a mudar a partir do último estágio pacífico, quando surge a propriedade particular e um sistema industrial fundamentado no trabalho assalariado. A partir deste fato, o consumo começa a superar o ócio como meio ordinário de decência. Com a difusão da comunicação e da mobilidade da população o indivíduo se expõe à observação de muitas pessoas que não possuem outro meio de julgar a boa reputação senão pela exibição de bens e, talvez de educação.

Ou seja, o único meio prático de impressionar os demais indivíduos é a demonstração interrupta da sua capacidade de pagar, que Veblen chama de Consumo Conspícuo. Vista como uma sociedade composta por pessoas com características ostentarias, tem a necessidade de exibir, de alguma forma, seus bens para os outros seres que com compõem este grupo.

O consumo de artigos de luxo, no seu real sentido, destina-se ao conforto do próprio consumidor e, portanto, atributo exclusivo das classes superiores. Enquanto que, a classe servil industrial, deve consumir apenas o necessário para à sua subsistência. Contudo, as classes mais baixas passam a desejar os mesmos artigos que as classes mais, porém, por não conseguirem pagar surgem produtos semelhantes, chamados de Emulação pecuniária.(VEBLEN, 1983) São artefatos mais baratos que visam imitar aqueles com um alto valor, destinados a sociedades mais abastadas, para que aqueles que não estão inseridos neste contexto também possam se sentir parte.

Weber (1956), antecessor de Veblen, elaborou a Teoria das Classes, sendo que elas eram principalmente baseadas no status e diferenciação por estilos. De modo que as classes superiores influenciavam as classes inferiores, fazendo com que esta desejasse possuir o mesmo estilo da classe dominante.

Ao encontro do pensamento de Weber, Simmel (1904) desenvolveu a teoria do Trickle-down, de modo que com o passar do tempo, produtos que apenas eram consumidos pelas classes mais altas, seja por valor ou preferência, passa a ser também utilizado por classes inferiores. Trickle-down, em tradução livre, pode ser entendido como o fenômeno de "gotejamento" ou "escorrimento".

Visto que o consumo estava diretamente ligado às classes sociais, Warner (1949) elaborou a Teoria da Construção de status e organização social. Definiu classe social como o 
O consumo: Revisão teórica sobre as possíveis razões do "ir às compras" por meio de infográfico

de Tobias Oliveira Camargo

grupo de pessoas vistas de forma semelhante pela sociedade, que interagem entre si - formal e informalmente - e partilham comportamentos. Constatou ainda, que a compra era uma das mais importantes expressões de alguma determinada posição de status dentro da sociedade e que cada classe social tinha motivações e comportamentos de compra únicos e distintos das demais.

Ao longo do século XX, prosseguindo com os estudos sobre sociedade e consumo, Bourdier (1979) desenvolveu a Teoria do Capital Cultural, composto de valores, práticas e preferências, que o indivíduo adquire ao longo da sua vida. Pode ser vista como uma forma de dominação, de modo que uma cultura se impõe sobre a outra. O gosto está relacionado ás preferências do indivíduo, onde este é formado a partir do seu capital cultural.

Portanto, este capital, influencia diretamente em suas escolhas na atividade de consumo, não há como dissociar capital cultural, gostos e consumo, pois estão interligadas e relacionadas. O trabalho de Holt (1998), além de trazer uma revisão teórica sobre diversos autores, apontou que quanto menor o capital cultural menor será a capacidade de significação, utilizam o produto exatamente como foi projeto. Ou seja, indivíduos com um maior capital cultural possuem uma maior capacidade de ressignificação, o que possibilita o uso dos artefatos em sentido para qual ele não foi projetado.

A partir dos anos 1960 e 1970 ocorreram mudanças nos formatos das pesquisas sobre o consumo, por conta da incapacidade de resposta da perspectiva anterior. Abordagens positivistas são capazes de responder o "como" os fatos acontecem, contudo uma abordagem não-positivista possibilita entender o "porquê" os fenômenos ocorrem.

Em seu artigo, Belk (1995) aborda a mudança de paradigma na pesquisa do consumidor. Inicialmente, elas tinham um caráter positivista, com métodos experimentais e surveys em uma abordagem quantitativa. Enfatizava questões econômicas e psicológicas, com foco no processo cognitivo que levava a compra. Os novos métodos de pesquisa do consumidor têm um caráter fenomenológico e interpretativista (não-positivista), com métodos etnográficos e exploratórios em uma abordagem qualitativa. Dá ênfase total às sociológicas antropológicas, com foco nas emoções que podem levar ao consumo.

As disciplinas relacionadas à economia possuem uma visão utilitarista e econômica do consumo, deixa muito a explicar sobre o porquê as pessoas comprar ou como escolhem os produtos que consomem. Douglas e Isherwood (2006) críticos desta visão, apresentam que o consumo não é baseado apenas em preço, mas em uma série de outras questões, que pode ser 
O consumo: Revisão teórica sobre as possíveis razões do "ir às compras" por meio de infográfico

de Tobias Oliveira Camargo

direcionada a partir da utilidade ou do gosto de cada consumidor, porém esta última, ainda é muito subjetiva e pouco determinada.

Como visto, não há uma data específica sobre quando deu início a revolução do consumo, mas acredita-se que ela foi antecessora à revolução industrial. Em todos os períodos esteve diretamente relacionado às relações sociais, muito mais do que uma demonstração de poder aquisitivo, delineava também as interações entre os sujeitos. No século XIX e XX, por domínio de modelos econômicos, o foco voltou-se em como vender mais e somente a partir de 1960 as pesquisas passaram a ter um caráter social e procuraram entender os porquês do consumo. O próximo tópico, dando continuidade à discussão do consumo ao longo dos períodos históricos, será discutido como ele se dá na pós-modernidade.

\subsection{Pós-modernidade}

Durante os "30 anos gloriosos" (1945 - 1973) havia uma despreocupação com o futuro, pautado no bem-estar social, a mitologia do consumo, contracultura e revolução sexual. Todos estes fatores geravam um clima de otimismo, algo que mudou a partir dos anos 1980 e 1990, subjacente à globalização e a revolução da informática, que conjugavam para comprimir o tempo e o espaço, ou seja, a lógica da brevidade e a libertação das limitações de localização. (LIPOVETSKY e CHARLES, 2004) Este período é chamado de pós-moderno, hipermodernidade ou, ainda, modernidade líquida. Para Bauman (2003), a situação atual se origina do derretimento dos grilhões e das algemas que limitavam a liberdade individual e, atualmente, ocorre à realocação dos poderes na modernidade.

Este termo tem o objetivo de apontar uma mudança de direção no modo de como às sociedades democráticas se organizavam socialmente e culturalmente. Tem como características a rápida expansão do consumo e da comunicação de massa, individualização, perda das paixões políticas e militâncias, e livre das utopias da modernidade.(BAUMAN, 2003) A hipermodernidade pode ser caracterizada como a época dos paradoxos, imediatismo, fim das guerras ideológicas e enfraquecimento das estruturas da sociedade, como a igreja, Estado e família.(LIPOVETSKY E CHARLES, 2004)

O imediatismo passou a compor o modo de vida em sociedade, pois os vínculos humanos são substituídos pela rapidez, os prazeres abstratos pelas intensidades aceleradas, as relações de proximidade deram lugar a intercâmbios virtuais. Portanto, é caracterizada pelo 
O consumo: Revisão teórica sobre as possíveis razões do "ir às compras" por meio de infográfico

de Tobias Oliveira Camargo

desempenho e eficiência e, claro, perde-se em profundidade, sensorialidade e solidez nas relações.

Estes autores, Bauman e Lipovetsky, se posicionam de uma maneira muito crítica com relação à sociedade de consumo. Ambos colocam que o objetivo principal na sociedade de consumidores, mesmo que não declarado, é elevar a condição dos consumidores à de mercadoria comerciável. Ou seja, os membros desta sociedade são as próprias mercadorias, são transformados em commodity. Contudo, esta visão permite compreender como são as relações sociais na contemporaneidade e, assim, melhor entender como o consumo participa e media as interações entre os indivíduos.

\subsection{O Consumo}

Durante os “30 anos gloriosos” Inicialmente é necessário compreender que há diversas visões sobre o consumo, sendo elas: Hedonista que afirma que o consumo é essencial para a felicidade e realização pessoal (mais popular); A visão moralista aborda a partir de uma ótica acusatória, alienadora e apocalíptica sobre o consumo; A naturalista afirma que é uma razão biológica ou uma universalidade humana.(ROCHA, In DOUGLAS e ISHERWOOD, 2006)

A naturalista tem relevância do fato que desde sempre a humanidade necessitou consumir para sua subsistência. A visão moralista encaixa-se com o pensamento de Bauman e Lipovetsky, pois afirma que a 'sociedade de consumidores' promove e encoraja ume estilo de vida e uma estratégia consumista que rejeita qualquer outra opção alternativa. Embora tenham certa razão, os sujeitos consumidores também contribuem para que a sociedade seja criada desta forma.

Contudo, o sujeito, mesmo que pertença uma classe baixa, não é apenas um ser ingênuo e manipulado, todos dentro desta sociedade são vítimas e cúmplices da ideologia do consumo.(BAUDRILLARD, 1991) Ou seja, o trabalhador não é uma vítima passiva, mas é conivente com o modo ao qual o sistema está configurado, pois "não faz sentido falar em irracionalidade do consumidor”.(DOUGLAS e ISHERWOOD, 2006: 108)

Enquanto a visão hedonista o trata como algo indispensável para a felicidade e conhecimento pessoal. Acredita-se que nenhuma delas esteja tão correta, mas o que acontece é uma mescla de todas elas, que pode variar de acordo com o capital cultural que cada sujeito carrega consigo. 
O consumo: Revisão teórica sobre as possíveis razões do "ir às compras" por meio de infográfico

de Tobias Oliveira Camargo

Bourdieu apresenta a teoria do Capital cultural, composto de valores, práticas e preferências, que o indivíduo adquiriu ao longo da sua vida. O gosto está relacionado ás preferências do indivíduo, onde este é formado a partir do seu capital cultural. Pode ser vista como uma forma de dominação, de modo que uma cultura se impõe sobre a outra. Se aproxima de Veblen quando discutem sobre a dominação cultural (capital cultural), onde uma cultura induz a ser como a outra.

Portanto, os bens cumprem o papel de marcadores sociais. Tem o objetivo de estruturar os valores que constroem as identidades e permitem a regulação social. E, os bens, são utilizados para expressar princípios, categorias, fixar e sustentar estilos de vida. (DOUGLAS e ISHERWOOD, 2006) Os artefatos cuja sua posse significa riqueza, não são apenas por conta do seu valor monetário, mas sim por as relações sociais que sustentam. Portanto, a pobreza não é definida por um inventário dos objetos, mas por um padrão de exclusões daqueles que não possuem tais bens.

O processo de consumo não está na lógica das necessidades ou da abundância, tampouco no valor de usos dos bens e serviços, mas na produção e manipulação dos seus significados $^{2}$. (BAUDRILLARD, 1991) Ocorre uma manipulação dos significados para distinção dos indivíduos e dos grupos, pois não se consome o objeto em si (valor de uso), mas seus significados. E, a partir disto, como cada indivíduo se insere na sociedade e a qual grupo ele pode vir a fazer a parte.

O significado reside em um mundo culturalmente instituído, de modo que para se tornar inerente aos bens é necessário que os valores deste mundo sejam transferidos para os artefatos. (McCRACKEN, 2003; DOUGLAS e ISHERWOOD, 2006) Quando estabelecida com êxito o interlocutor será capaz de ler claramente os códigos, pois será ele o responsável por esta transferência de propriedades significativas. Desta comunicação, poderá informar a todos os demais quem ele é, quais são seus grupos sociais e seu papel dentro deste contexto.(BOURDIEU, 1979)

Os objetos contribuem para a construção do mundo a qual a nossa cultura está inserida, pois tem o papel de tornar visível e tangível estes valores, tornam a cultura em algo material. Permitem a discriminação de outros indivíduos que não partilham dos mesmos códigos e, portanto não são capazes de ler e interpretar os mesmos códigos simbólicos. (BAUDRILLARD, 1991) Os bens são capazes de distinguir duas categorias apenas por o

\footnotetext{
${ }^{2}$ Tomemos o conceito de Greimas (1975) de significado, como significações recobertas por o significante e
} manifestadas graças a sua existência. Aquilo que se entende do objeto, ou seja, seu conteúdo. 
O consumo: Revisão teórica sobre as possíveis razões do "ir às compras" por meio de infográfico

de Tobias Oliveira Camargo

valor simbólico diferentes que uma delas dá a um mesmo artefato. Um dos modos de apresentar esses valores aos mais jovens e marcar o tempo é por meio de rituais.

Os rituais são convenções que constituem definições públicas visíveis, busca a materialização dos significados por meio dos objetos. (DOUGLAS e ISHERWOOD, 2006; McCRACKEN, 2003; BELK, 1995) O ritual é uma oportunidade para afirmar, evocar, assinalar ou revisar símbolos e significados convencionais da ordem cultural. Quanto mais caro e pomposo o ritual, mais forte é a intenção de fixar tais sentidos. Inclusive, são formas de marcar a passagem do tempo e construir a memória de cada indivíduo.

Portanto, ao passo que ele determina as relações sociais, o consumo como processo de objetivação, de modo que a utilização dos artefatos torna-se simultaneamente uma prática no mundo e contribui na compreensão dos próprios indivíduos, do mundo a sua volta e como se relacionam. (DOUGLAS e ISHERWOOD, 2006; MILLER, 1995) Ou seja, os bens são utilizados para a construção e entendimento da realidade e do self (identidade). "A atividade consumir pode ser considerada um caminho vital e necessário para o autoconhecimento, ao mesmo que o mercado começa a se tornar indispensável para processo de descoberta de quem realmente somos." (CAMPBELL, 2006: 52) Os sujeitos se descobrem ao se exporem a uma grande variedade de produtos e serviços, ou seja, o consumo oferece o significado e a identidade que todos buscam.

O "ir as compras" se tornou um hábito incorporado no comportamento das pessoas, com, o objetivo de obter as habilidades necessárias (BAUMAN, 2008), ou seja, ser aceito em determinado grupo e, inclusive, como forma de auto descoberta(CAMPBELL, 2000; BAUDRILLARD, 1991). Em vista da volatilidade das identidades, as pessoas tem a necessidade de "comprar" artefatos para que ele contribua no processo de autoconhecimento de sua identidade e, então, adentrar como membro de algum grupo.

Desta forma, o consumismo moderno "é tudo menos materialista", pois se realmente desejassem a posse dos bens materiais, as pessoas iriam primar pela sua acumulação e não pelo descarte.(CAMPBELL, 2000) O desejo dos consumidores é experimentar na vida real os prazeres vivenciados na imaginação e cada novo artefato é uma oportunidade para fazê-lo. Como a realidade, nem sempre é como se imagina, gera uma decepção e, portanto, explica o fato de sempre consumirem novos produtos. O consumo tem como o seu objetivo máximo alcançar a felicidade por meio dos da significação dada aos artefatos adquiridos. (BAUDRILLARD, 1991) 
O consumo: Revisão teórica sobre as possíveis razões do "ir às compras" por meio de infográfico

de Tobias Oliveira Camargo

Embora o consumidor hipermoderno tenha o frenesi do "sempre mais" não deixa de considerar questões qualitativas. (LIPOVETSKY e CHARLES, 2004) Ou seja, embora tenha o desejo de consumir uma grande quantidade de produtos, ele ainda procura por o artefato com as melhores características. Critérios como o bem-estar, e aspectos sensoriais e culturais, são indissociáveis no consumo pós-moderno.

Em um contraponto à visão utilitarista, o consumo passa a ser entendido como uma expressão de estilos de vida e como extensão do self. (BELK, 1995) Em síntese, o descobrimento e expressões do self, a marcação social, a transferência de significados para os artefatos de acordo com cada cultura e rituais são entendidas como parte fundamental da atividade de consumo e serão apresentadas em um formato de infográfico.

\section{INFOGRÁFICO}

A sua leitura inicia-se na parte inferior e apresenta os quatro conceitos principais, identificados neste artigo, como fundamentais para entender o consumo, sendo eles: status (marcado social), significação, identidade e rituais. Estes caminhos levarão aos autores que falam sobre cada conceito e dentro de seus quadros são apresentados os principais pontos da sua teoria para facilitar a compreensão de o porquê de eles serem apresentados, e, ordem de publicação da mais recente para a mais antiga.

Na lateral esquerda há uma linha temporal que mostra a distribuição das teorias ao longo do tempo, pois é necessário contextualizar a época em que cada autor viveu e desenvolveu seu trabalho. Pois, como visto, consumo e sociedade sempre estiveram diretamente relacionados.

No centro do infográfico há duas linhas (na cor verde) secundárias que apresentam os autores que possuem uma visão crítica sobre o consumo e se contrapõem aos demais, e aqueles em que sua teoria não tem o foco no consumo, mas aparece como reflexo do seu o estudo sobre a sociedade.

$\mathrm{Na}$ parte superior são apresentadas três teorias sobre as origens do consumo. Aparecem fora dos eixos, pois são teorias diferentes sobre o mesmo tema. Foram pesquisadas que não abordam o contexto em que os autores estavam inseridos e, portanto, não poderiam compor a ordem cronológica dos demais autores. 
O consumo: Revisão teórica sobre as possíveis razões do "ir às compras" por meio de infográfico

de Tobias Oliveira Camargo

Este infográfico apenas expressa uma síntese geral sobre as teorias e autores, algumas relações entre eles que se referem às conclusões deste trabalho, portanto, talvez seja necessária a sua leitura completa para compreender o que está sendo proposto e pode não fazer sentido o infográfico fora de seu contexto.

Fig. 1 - Infográfico

Fonte: Do autor 
O consumo: Revisão teórica sobre as possíveis razões do "ir às compras" por meio de infográfico

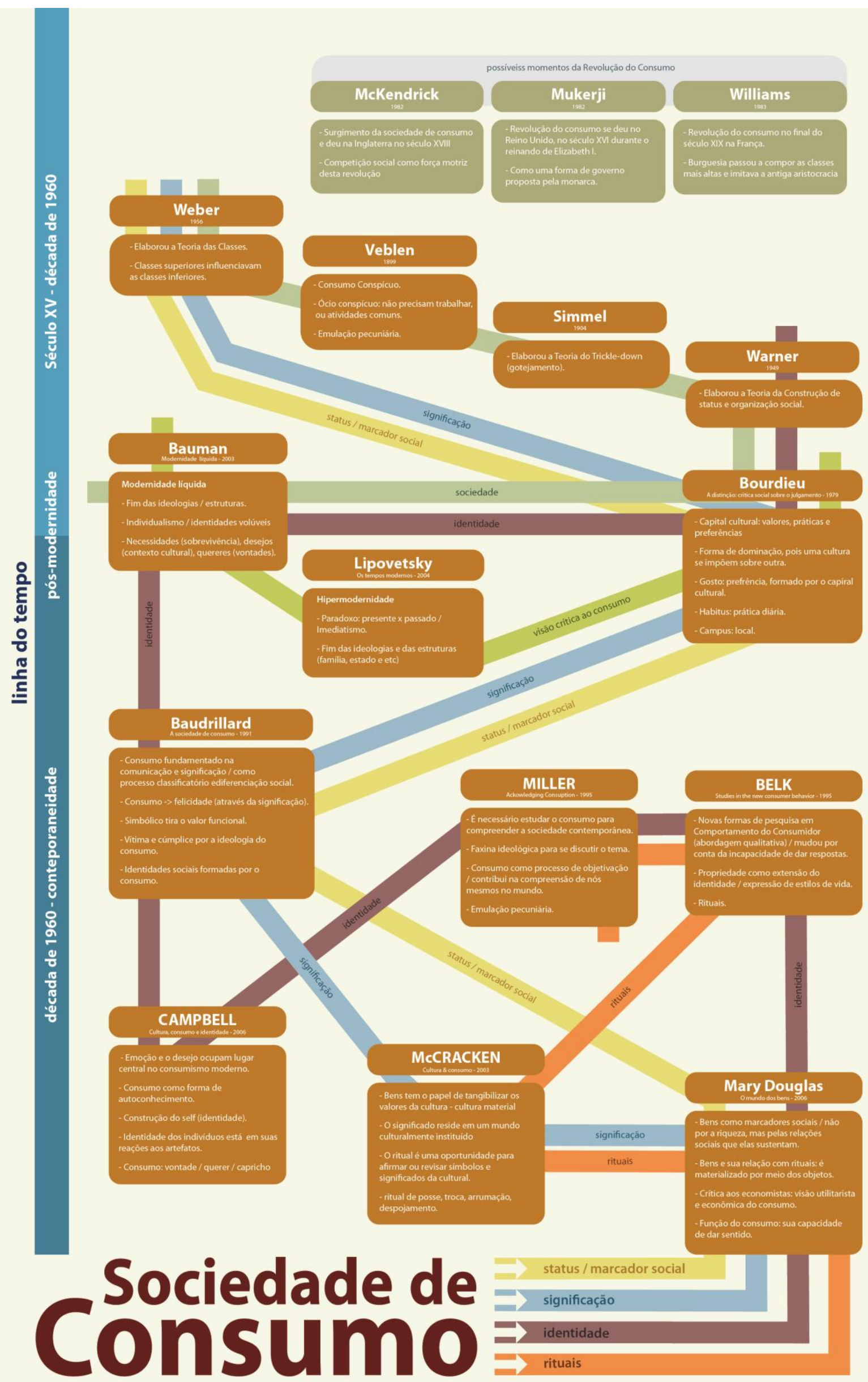


O consumo: Revisão teórica sobre as possíveis razões do "ir às compras" por meio de infográfico

de Tobias Oliveira Camargo

\section{CONSIDERAÇÕES FINAIS}

O objetivo do trabalho constitui-se em promover uma discussão teórica sobre a sociedade de consumo com base nos principais autores associados ao consumo, para discutir os motivos trazidos por eles que poderiam levar ao consumo, por fim, sintetizar as abordagens teóricas em um infográfico.

Bauman, Lipovetsky e Baudrillard discutem que a cultura pós-moderna é a própria cultura do consumo. Enquanto Miller, McCracken, Campbell, Bourdieu e Douglas, deixam de lado a discussão da pós-modernidade e focam nas razões, modos, circunstâncias e porquês que levam as pessoas a consumirem. Suas teorias aproximam-se das de Veblen, pois tem em seu foco de estudo a sociedade, e suas principais contribuições estão relacionadas à Teoria das Classes. Bourdieu apresenta a teoria do Capital cultural, que está diretamente relacionado à Veblen, quando discutem sobre a dominação cultural (capital cultural).

Baudrillard apresenta o Consumo fundamentado na comunicação e significação por meio dos bens, como processo de classificação social. Tem relação próxima às teorias de Veblen, Bourdieu, Douglas e McCracken quando afirma que as identidades sociais são formadas a partir do consumo. Do mesmo modo, Campbell coloca o consumo como uma forma de autoconhecimento e construção do self (identidade).

Douglas apresenta os Bens como marcadores sociais, não por seu valor monetário, mas pelas relações sociais que sustentam. Da mesma forma, McCracken coloca que os objetos contribuem na construção da sociedade a qual uma determinada cultura está inserida e sua função é dar visibilidade e tangibilidade a estes valores. Para Douglas, McCracken, Belk estas relações sociais são difundidas e repassas para os demais membros por meio dos rituais.

Em suma, a partir dos autores tem-se que os possíveis motivos que podem levar o indivíduo a consumir, encontram-se na descoberta e expressão da identidade (self), no marcador social (status), na transferência de significados (significação) para os artefatos de acordo com cada cultura e nos rituais. Esses quatro podem ser entendidos como partes que compõem a atividade de consumo, conforme apresenta o infográfico.

\section{REFERÊNCIAS BIBLIOGRÁFICAS}


O consumo: Revisão teórica sobre as possíveis razões do "ir às compras" por meio de infográfico

de Tobias Oliveira Camargo

BAUDRILLARD, J. A sociedade de consumo. Lisboa: Edições 70, 1991.

BAUMAN, Z. Modernidade líquida. Rio de Janeiro: Zahar, 2003.

BAUMAN, Z. Vida para consumo: a transformação das pessoas em mercadorias. Rio de Janeiro: Jorge Zahar, 2008.

BELK, R. Studies in the new consumer behavior. In: MILLER, Daniel. Ackowledging Consuption: A review of new studies. Londres: Routledge, 1995.

BOURDIEU, P. La distinction: Critique sociale dujugement. Paris: Minuit, 1979.

CAMPBELL, C. Cultura, consumo e identidade. Organizadores Lívia Barbosa, Colin Campbell. Rio de Janeiro: Editora FGV, 2006.

CAMPBELL, C. A ética romântica e o espírito de consumismo moderno. Rio de Janeiro: Rocco, 2000.

CUNHA, A. G. Dicionário Etimológico da Língua Portuguesa. Rio de Janeiro: Lexikon, 2010.

DOUGLAS, M.; ISHERWOOD, B. O mundo dos bens: para uma antropologia do consumo. Rio de Janeiro: Editora UFRJ, 2006.

GREIMAS, A. J. Sobre o sentido. Petrópolis: Vozes, 1975.

HOLT, D. B. Does Cultural Capital Structure American Consumption?. The Journal of Consumer Research, Vol. 25, No. 1. (Jun., 1998): 1-25.

LIPOVETSKY, G.; CHARLES, S. Os tempos hipermodernos. São Paulo: Barcarolla, 2004.

McCRACKEN, G. Cultura \& consumo: novas abordagens ao caráter simbólico dos bens e das atividades de consumo. Rio de Janeiro: Mauad, 2003.

MILLER, D.. Ackowledging Consuption: a review of new studies. Londres: Routledge, 1995.

SIMMEL, G. "Fashion." International Quarterly, Vol. 10, 1904: 130-150.

VEBLEN, T. B.. A Teoria da Classe Ociosa. São Paulo: Abril Cultura, 1983.

Warner, W.L. et al. Social class in America. Science Research Associates, Chicago, 1949.

WEBER, M. Economy and Society. Berkeley: University of California Press, 1956.

Artigo submetido: 05/08/2015

Artigo aprovado: 21/11/2015 